\title{
El Conde de Morphy (1836-1899) en la Corte de los Borbones. Historia de una familia irlandesa en España (ss. XVIII-XIX)
}

\author{
Beatriz García-Álvarez de la Villa \\ Universidad de Oviedo, España
}

Copyright (c) 2019 by Beatriz García-Álvarez de la Villa. This text may be archived and redistributed both in electronic form and in hard copy, provided that the author and journal are properly cited and no fee is charged for access.

\begin{abstract}
In recent times there has been an increasing interest in the study of foreign groups which were part of the circle of influence of Spanish monarchs. The role of these groups in Spanish society has also been a matter of concern. Irish exiles in Spain have been the subject of analysis because of their connection to the elites in power. In the present study, the focus lies on one particular Irish family, the Murphys, in order to ascertain their social and economic progress throughout different generations as well as their level of integration in Spain. The fidelity shown to the Spanish crown, grounded on the Catholic faith and on a record of services to the monarchy, was instrumental for Guillermo Morphy, later Count of Morphy, to be chosen as a trustworthy individual at the court of the Bourbon Dinasty. As a tutor and accompanying gentleman, he would guide the education of Prince Alfonso on solid moral and intellectual principles. When the prince was crowned King as Alfonso XII, he named Guillermo Morphy as his personal secretary. From this position, the Count of Morphy exerted a powerful influence, carrying out several projects on political reform.
\end{abstract}

Key Words. Exile, Monarchy, Spanish Court, Commerce, Murphy Family, Count of Morphy, Alfonso XII, Education, Spanish Regenerationism.

Resumen. En los últimos años hemos asistido a un creciente interés sobre grupos extranjeros acogidos por la Monarquía hispánica y su papel en la sociedad española. De especial interés para los estudiosos ha sido el caso de los irlandeses exiliados a España por sus fuertes implicaciones en las élites de poder. Nuestro estudio basado en una familia de ascendencia irlandesa, los Murphy, reconstruye sus redes familiares para comprender su integración en España y su ascenso social y económico, durante varias generaciones. Asimismo, muestra como los vínculos de fidelidad establecidos con la Monarquía española, en base a su catolicismo y servicios a la Corona, influirán para que Guillermo Morphy, más tarde Conde de Morphy, sea elegido persona de confianza en la corte borbónica. Desde sus cargos como gentilhombre y jefe de estudios guiará la 
formación intelectual y moral del Príncipe Alfonso, al hacerse cargo de su educación. En el momento en que Alfonso XII fue proclamado rey de España le nombró su secretario particular, cargo desde el que Morphy continúo ejerciendo una beneficiosa influencia, llevando a cabo diversos proyectos regeneracionistas.

Palabras clave. Exilio, monarquía, corte, comercio, familia Murphy, Conde de Morphy, Alfonso XII, Educación, Regeneracionismo.

\section{Introducción}

En Redes de nación y espacios de poder (2012), Recio Morales señala la importancia del estudio de las familias pertenecientes a comunidades de inmigrantes y su trayectoria en España, a través de diferentes generaciones (48). Dentro de este estudio, los irlandeses exiliados a España ocupan un lugar destacado por sus fuertes implicaciones en las élites de poder, ya que "en el caso de la Monarquía hispánica, al pertenecer a un mismo universo cultural, la identificación con los valores sociales de la sociedad de acogida fue total" (46). Muchos de ellos, pertenecientes a la nobleza y con experiencia en el comercio, al sufrir la pérdida de su poder e influencia durante las guerras de Cromwell, a causa de su religión católica, se sintieron atraídos por el comercio colonial y por los privilegios que la Monarquía española les otorgaba (García-Álvarez de la Villa y Terry 73). La comunidad irlandesa representaba, hacia 1750, el 18 por ciento de los extranjeros en Cádiz, constituyendo el tercer grupo más numeroso, después de los genoveses y franceses (Bustos 141). La Monarquía española no se olvidó de la cuestión irlandesa y tomó a los exiliados irlandeses bajo su protección. Así, en 1759 se aprobaría un Real Decreto por el cual cada irlandés establecido en España durante un tiempo superior a diez años, o que hubiera contraído matrimonio con una española, adquiriría los mismos derechos que cualquier oriundo español (Fannin, "The Irish Community"). Esto posibilitó el que muchas familias irlandesas asentadas en España alcanzaran rápidamente un papel relevante en los negocios y expandieran su influencia al ocupar cargos importantes en la administración y en la corte. Su prestigio fue incrementado al alcanzar títulos nobiliarios, muchas veces en recompensa a sus servicios a la corona española dentro del ejército. Recio Morales (26-7) nos habla sobre la relación entre los irlandeses y la Monarquía española:

Una lógica patronazgo-fidelidad dinástica que exigió a ambos socios unas responsabilidades muy concretas: la Corona reconoció a los irlandeses unos derechos que se reflejaron en un amplio abanico de mercedes y el mantenimiento de un gran número de irlandeses a su servicio; a cambio, la Monarquía exigió a los irlandeses fidelidad dinástica absoluta. Esta relación funcionó tanto con los Austrias como con los Borbones.

A mediados del s. XVIII son abundantes los apellidos de origen irlandés localizados en los archivos de Andalucía. Terry, MacNamara, Power, Quinlan, O’Brien, Quilty, Shesty, Malloy o Murphy son algunas de las familias que deciden establecerse en España buscando nuevas oportunidades (Fannin, "Spanish Archives" 2). En un trabajo anterior hemos seguido la trayectoria de la familia Terry en España (García-Álvarez de 
la Villa y Terry). En esta ocasión, presentamos la historia de otra familia de origen irlandés, los Murphy, naturales de Waterford, establecida en Málaga. Para ello hemos estudiado la genealogía de Guillermo Morphy, el Conde de Morphy (1836-1899), gracias a los archivos privados pertenecientes a esta familia, así como a la abundante documentación localizada en otros archivos españoles, citados al final de este artículo. De este modo, en la primera parte de este trabajo se muestran sus orígenes, actividades económicas y vínculos con la monarquía a lo largo de varias generaciones, mostrando como a raíz de su exilio, la familia Murphy se consolida durante la segunda mitad del siglo XVIII en el comercio internacional como una importante "dinastía". Posteriormente, en el siglo XIX, algunos de sus miembros se incorporan al ejército o buscan otras perspectivas en el consulado, en la administración o en la Corte, desde donde van a mostrar su fidelidad a la corona española. Por otro lado, dedicamos la segunda parte de este trabajo a la figura singular de Guillermo Morphy, el Conde de Morphy, quien ocupó los cargos de gentilhombre, jefe de estudios y secretario personal, ejerciendo un papel relevante en la educación del príncipe Alfonso, ${ }^{1}$ que ha sido frecuentemente desestimada por los investigadores. Nuestro propósito es profundizar en este aspecto, prestando una especial atención a los propósitos de su programa de enseñanza y sus aspiraciones regeneracionistas respecto a la Restauración. Con ello esperamos que esta investigación sea una aportación a los recientes estudios sobre la Corte y monarquía española del siglo XIX que acaparan hoy la atención de la historiografía. $^{2}$

\section{Los orígenes de Murphy}

De acuerdo a O'Hart en Irish Pedigrees (691) O’Murphy o Murphy ${ }^{3}$ son formas modernizadas y anglicadas que tienen su origen del clan O'Morchoe. ${ }^{4}$ Esta familia procede del condado de Wexford. ${ }^{5}$ Durante el reinado de Eduardo VI de Inglaterra, la familia de los O'Morchoe sufrió la confiscación de sus propiedades por la corona y muchos de sus miembros se dispersaron, estableciéndose en Carlow, Kilkenny, y otras comarcas irlandesas próximas, donde llegaron a ser muy numerosos. Durante los reinados de Isabel I y Jacobo I, parte de sus posesiones confiscadas les fueron devueltas por su fidelidad y servicios en el ejército. Posteriormente, durante el periodo de Cromwell y tras la capitulación de Limerick en 1691, muchos de ellos siguieron a Patrick Sarsfield a Francia para ponerse a las órdenes del rey exiliado Jacobo II, mientras otros buscaron refugio en España y en otros países, donde fueron distinguidos en armas (O'Hart 693).

Uno de los miembros de esta antigua familia irlandesa es Timothy O'Morphy (nacido hacia 1603) escudero de Graig Namanach en el condado de Kilkenny. Sus descendientes se establecerían en Waterford, cuyo puerto tuvo una importante actividad comercial durante el s. XVIII, siendo intermediario de las mercancías españolas que finalmente llegaban a los puertos de las islas Británicas. Los Murphy no fueron ajenos a estas actividades y tras establecerse en Málaga continuaron sus actividades en el comercio. Según Fannin (2013: 2), esta rama pertenece a una de las principales familias nobles irlandesas de la región, portadora de armas. El escudo de armas conservado por la familia (archivo privado de la autora) se presenta partido: en plata, dos leones rampantes, linguados, de gules, en el primer y cuarto cuartel; en gules, dos leones rampantes, linguados, en plata, en el segundo y tercer cuartel; fajado de sable y cargado de tres haces de mieses de oro puestas en aspa. 


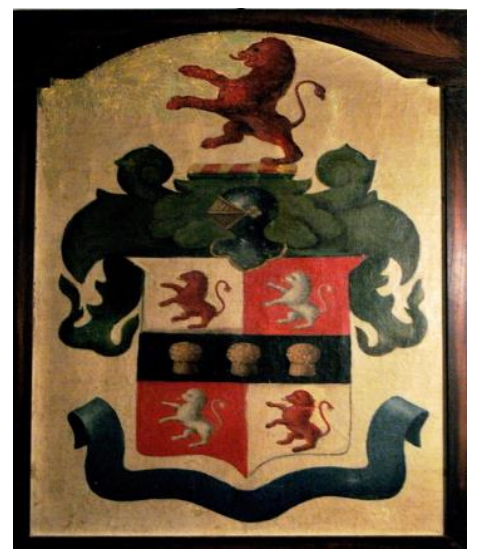

\section{Una familia de comerciantes en el exilio: Juan Murphy Elliot}

Bajo el reinado de Carlos III, se aprueba el Decreto para el Comercio Libre con fecha de 16 de octubre de 1765, lo que supuso un gran impulso del comercio colonial al incluirse cinco puertos de América y nueve españoles. Entre estos últimos, aparece el puerto de Málaga, que comienza un considerable comercio libre con las colonias americanas, atrayendo a un gran número de extranjeros. Entre ellos encontramos a John Murphy Murphy, procedente de Waterford, involucrado de lleno en el comercio, que aparece ya como un importante hombre de negocios, propietario de varias embarcaciones (Fannin, "Spanish Archives" 2).

John Murphy contrajo matrimonio con Catalina Elliot. De esta unión nace en Waterford en 1730 John Morphy Elliot, quien se dedicará a los negocios coloniales de su padre, incrementando su presencia en el comercio colonial. Conocemos más datos de este personaje por un litigio conservado en la Chancillería de Granada, fechado el 25 de enero de 1800. ${ }^{6}$ En el mismo, Juan Morphy Elliot declara pertenecer a una de las principales familias nobles de Irlanda, a quienes por su condición de católicas se les confiscaron muchos de sus bienes. Obtenida su carta de naturaleza, se queja de la vulneración de sus derechos en el comercio marítimo al que se dedica junto a sus hijos. Lo cierto es que los privilegios otorgados por la Corona española a aquellos extranjeros a quienes se les reconocía su condición de nobleza, es decir, el derecho a comerciar y no pagar impuestos, daba lugar a frecuentes enfrentamientos con los comerciantes locales pertenecientes a la Asociación del Comercio Marítimo (Fannin, "Spanish Archives" 3). Juan Morphy Elliot aparece como una persona con experiencia en el tráfico marítimo, fundador de la compañía Juan Murphy y Cía. y propietario de dos buques mercantes, "La esperanza" y "El ligero", con los que se dedica al comercio del vino, ropas y bebidas espiritosas (3). Su éxito en los negocios le lleva en 1785 a aparecer como uno de los directores de la Compañía de Navieros de Málaga. Según señala González Mireles ("Retrato" 9), a través de esta sociedad anónima de navíos dedicada al "transporte del monopolio de papel, para tabacos y baraja", la familia Murphy se consolida como una importante dinastía comercial. Sus negocios con el monopolio del papel, que era fundamental para la hacienda española, se va a extender, entre otras plazas, a Nueva España, Cuba, los puertos del oeste norteamericano, Cádiz, Gran Bretaña, Hamburgo, Gibraltar, Caracas y Jamaica (9). En 1790, continúa su ascenso y pasa a ser director de La Marítima, fruto de la fusión de la anterior compañía con la Compañía Naviera de Caracas. 
Figura 1. Genealogía de Guillermo Morphy, Conde de Morphy ${ }^{7}$

\author{
Thimothy O’Morphy (1603) x Eleonor O’Neill \\ Escudero Kilkenny \\ Jacobo O’Morphy (1634) x Alfonza Morphy \\ Escudero de Waterford \\ Francisco Murphy (1670) x Mary Murphy \\ Escudero de Waterford \\ John Murphy (1705) x Kathleen Elliot \\ Escudero de Waterford \\ Juan Morphy (1730) x Bárbara Porro \\ Waterford
}

Juan Morphy Elliot se une en matrimonio con Bárbara Porro, nacida en Gibraltar en 1738, hija de Tomás Porro, procedente de una familia noble de Génova (Cadenas 131). Esta estratégica unión contribuyó a incrementar su poder en los negocios, materializándose en la Casa Morphy y Porro. Parte del capital obtenido por la familia Murphy fue invertido en fincas rústicas y urbanas. Además, Juan Morphy Elliot aumentó su patrimonio familiar con la instauración de una fábrica de aguardiente en Casabermeja, donde tenía su residencia. En este municipio malagueño obtendrá en 1788 el título de hidalguía. A través de la Certificación de Nobleza emitida por el Obispo Roberto Walsh, de Waterford (131), conocemos que de su matrimonio con Bárbara Porro nacieron cinco hijos, tres de ellos varones, Juan, Mateo y Thomas. Esta red familiar va a garantizar no solo la pervivencia de los negocios de Juan Morphy Elliot, sino que además logrará acrecentar su ascenso en el mercado internacional.

\title{
4. Las casas comerciales: Morphy y Porro y Gordon \& Murphy
}

Los negocios de la familia Murphy continuaron beneficiándose de la política aperturista llevada a cabo por Carlos III. En 1778 la aprobación del reglamento y aranceles reales para el comercio libre de España y las Indias supuso para el comercio internacional la ampliación del número de plazas a Montevideo, Buenos Aires y Río de la Plata. Posteriormente, en 1789, otra Real Orden dictamina la apertura del puerto de Veracruz al comercio libre (Bernal). Veracruz se convirtió en una de las plazas de mayor interés para la familia Murphy, donde se establecieron Thomas y Mateo, mientras que Juan participaba de los negocios de su padre, desde Londres y Cádiz, a través de la Casa Juan Morphy y compañía (Gámez 132-134).

Los hermanos Murphy y Porro lograran a través de la cohesión de sus casas comerciales, con fuertes vínculos familiares, incrementar su poder económico de manera espectacular a finales del s. XVIII. En el Archivo Histórico Nacional ${ }^{8}$ se conservan varios documentos que constatan los negocios llevados a cabo por Juan y Tomás/Thomas Murphy con su tío materno Pedro Porro. Así sabemos que, con el 
propósito de ayudar en los negocios familiares, Tomás Murphy, natural de Málaga, solicita permiso en 1791, para embarcar junto a Pedro Porro, encargado de los negocios de la Compañía Marítima de Málaga, en la fragata de la misma "La Prosperidad", con destino a Veracruz, donde establecerá su residencia. La trayectoria de Tomás Murphy ha sido estudiada por González Mireles, quien señala que fruto de esta colaboración fue el nacimiento de la casa Murphy y Porro en 1795, dedicada al comercio de vino, aceite, azúcar, cereales, harina y algodón ("La cuestión” 236). Asimismo, explica cómo las medidas adoptadas por la Corona española beneficiaron a los negocios de la Casa Murphy y Porro al permitir aquella el llamado "comercio neutral" dando acceso a la entrada en sus puertos de barcos extranjeros que portaban banderas neutrales y posibilitando "las asociaciones con casas de comercio estadounidenses" (237).

En 1797 Tomás Murphy contrae matrimonio con Manuela Alegría, prima de José de Azanza y Alegría, duque de Santa Fe, ministro de guerra en España y posteriormente virrey de la Nueva España (México). La unión matrimonial no solo sirvió a Tomás para ascender dentro de la élite de Veracruz, sino que además le facilitó licencias y contratas con el gobierno gracias a la influencia del virrey Azanza (González Mireles, "Retrato" 18).

González Mireles (“La cuestión” 237) también nos aporta información de interés sobre Juan Morphy y Porro, quien entró en negocios con Guillermo Gordon, miembro del parlamento inglés, fundando en 1805 la casa comercial Gordon \& Murphy, en Londres. Esta alcanzaría grandes éxitos comerciales y económicos al servir como intermediaria entre la Corona española y la Corona británica. También se involucró Thomas Murphy en el negocio de la casa Gordon \& Murphy, convirtiéndose en su agente principal en México (1805-1809). Los negocios familiares se beneficiaron de la confianza de la Corona española, que a cambio obtenía beneficios con los que aliviar los problemas por los que pasaba la Real Hacienda (González Mireles, Tesis 137-138). Tomás, Mateo y Juan Murphy como agentes de Gordon \& Murphy establecieron contacto con altos funcionarios de los gobiernos inglés y español consiguiendo las contratas más importantes de la época (Tesis 112-3).

La experiencia y el conocimiento en materia comercial le llevaron a Tomás Murphy a participar en las sesiones de las Cortes de Madrid entre 1821 y 1822 como diputado en representación de la provincia de México. Entre sus demandas estaban: la igualdad entre españoles a ambos lados del océano y la protección de los productos nacionales mediante la exigencia del pago de impuestos a los extranjeros, con el objeto de favorecer la agricultura e industria nacional (González Mireles, "La cuestión" 240).

Años más tarde, la casa Gordon \& Murphy se unió a Co. Blanco (Blanco White 26). Blanco White mantuvo amistad con Juan Morphy y Porro, con quien compartía la misma afición por la música. Este último era coronel español y vivía en Londres en un ambiente de refinamiento y cultura. Así nos lo cuenta el propio Blanco White:

Sucedió por aquel tiempo que el coronel [don Juan] Murphy, español de origen irlandés, que había conocido ligeramente en Madrid, al enterarse de que estaba en Londres me invitó a su casa. Él era también buen aficionado a la música y al enterarse de que tocaba el violín aceptablemente me invitó a que me uniera a un cuarteto que se reunía todas las semanas en su casa en el ambiente más agradable y selecto que se podía esperar ... Sólo los iniciados en los misterios de la música pueden hacerse idea de la exquisitez de nuestro entretenimiento. Mi amigo Murphy estaba entonces en el apogeo de su prosperidad comercial porque, además de la graduación española de coronel, era socio de la firma Gordon and Murphy, establecimiento que durante la 
guerra con España había obtenido ganancias considerables por medio de un contrato con el gobierno español en el que tenía parte el gabinete inglés. El objeto del contrato era una determinada cantidad de plata de las minas de Méjico. El coronel Murphy, que aun en medio de las desgracias que han ensombrecido la última parte de su vida, ha seguido siendo un hombre amable y generoso, era todo amistad y hospitalidad en su época de prosperidad. (238)

Pero la vida de Juan Morphy y Porro sufrió un giro importante a raíz de los acontecimientos de 1808, como consecuencia del motín de Aranjuez, la abdicación de Carlos IV y la llegada a Madrid de Fernando VII. Juan Morphy y Porro se puso al servicio del rey, como coronel de infantería, para combatir a los franceses, fue hecho prisionero y trasladado a Bayona. En 1820 la Corona española le otorgaría el hábito de la Orden de Alcántara como recompensa por sus servicios en el ejército (Cadenas y Vicent 131).

Figura 2. Genealogía de Guillermo Morphy, Conde de Morphy ${ }^{9}$

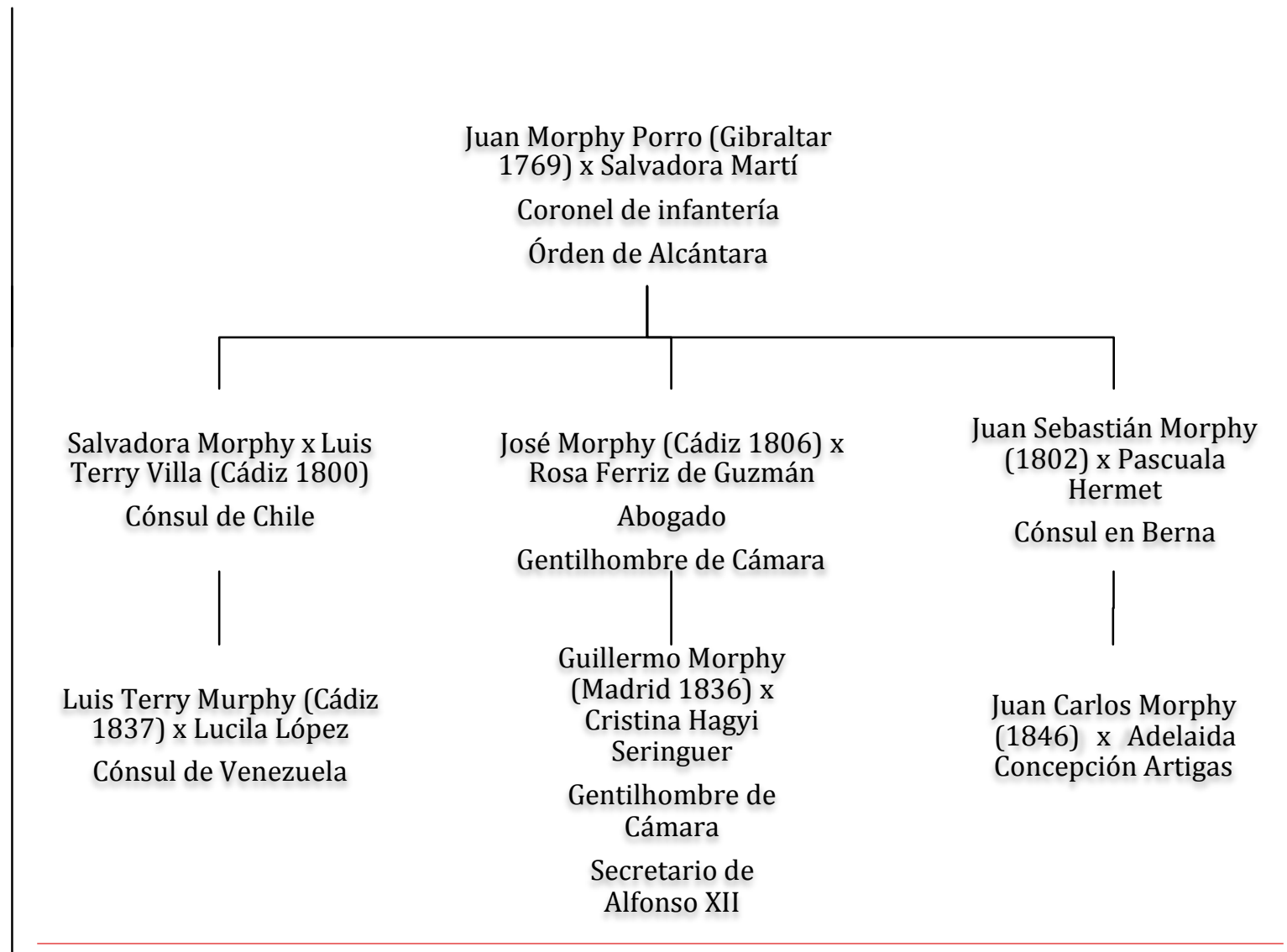

Del matrimonio de Juan Morphy y Porro con Salvadora Martí y Seguí, natural de Cádiz, nacieron varios hijos. Esta generación siguiente mantendrá su nivel social ocupando cargos relevantes dentro de la diplomacia y de la jurisprudencia. Así, encontramos a Juan Sebastián Morphy y Martí como Cónsul de España en Alejandría (1867) y posteriormente en Tetuán (1878); su hijo Juan Morphy y Hermet será Cónsul de España en Berna (1897); ${ }^{10}$ por su parte, Salvadora Morphy y Martí contrae matrimonio con el Cónsul de Chile y Nicaragua en Cádiz, Luis Terry Villa, también de descendencia 
irlandesa y perteneciente a la oligarquía gaditana, con negocios en la industria textil, seguros y el sector bancario (García-Álvarez de la Villa y Terry 77); por último, José Morphy y Martí, de quien nos ocupamos seguidamente, se dedicará a las leyes y ampliará las redes sociales familiares al establecerse dentro de la Corte de los Borbones.

\section{Un gentilhombre en la corte de Isabel II: José Morphy}

José Morphy y Martí nació en Cádiz en 1806. Fue alcalde de Navalcarnero y ocupó durante el reinado de Isabel II diversos cargos como juez de primera instancia en Almería, ascendiendo a fiscal de la audiencia de Sevilla, magistrado honorario de la Audiencia de Albacete y juez de la Corte. Todos estos nombramientos se realizaban por designación real, tras ser propuestos por el Consejo de Estado. Asimismo sabemos por el certificado de matrimonio expedido en la Iglesia parroquial de San Martín de Madrid el 30 de junio de 1833, que José Morphy contrajo matrimonio con Rosa Ferriz de Guzmán, hija de Pedro Ferriz de Guzmán, capitán de navío, perteneciente al cuerpo de ingenieros de Marina de la Real Armada, destinado al departamento de Cádiz.

El 9 de abril de 1850 la reina Isabel II le distingue con el nombramiento de Gentilhombre de Cámara. ${ }^{11}$ Según Raquel Sánchez (2018), el gentilhombre servía al monarca y sus familiares, recibiendo a cambio honor y prestigio social por el ejercicio del cargo (36). Tradicionalmente, dentro de los diferentes tipos de esta figura, de cámara, de entrada, con o sin ejercicio, entre otros, el Gentilhombre de Cámara ostentaba una categoría principal, junto a los de casa y boca, dada su mayor proximidad al rey, pudiendo acceder con libertad a las diferentes cámaras o aposentos reales (36). Con la reina Isabel II este cargo pasa a tener un significado más honorífico (37).

A causa de la Revolución del 1854 José Morphy quedó cesante de su trabajo como abogado al servicio del Estado, dedicándose a partir de entonces "al despacho de sus negocios como jurisperito", trasladándose a Sevilla, donde ocupó el cargo de Fiscal de la Real Audiencia Territorial de Sevilla (Ovilo y Otero 337). El 16 de noviembre de 1858 fallece a los 52 años de edad, siendo enterrado en Madrid en el Cementerio de la Real Archicofradía Sacramental de San Martín. En su testamento, deja expreso encargo de que la conducción del cadáver se realice a hombros y que todo lo relativo al entierro se haga sin ostentación, de modo que los gastos que le podrían ocasionar se dedicasen a misas y limosnas para los pobres necesitados; asimismo pide que se mandasen decir cincuenta misas con limosna de seis reales cada una. Nombró como único y universal heredero a su hijo Guillermo Morphy. ${ }^{12}$ A raíz de su fallecimiento, su esposa Rosa Ferriz y Guzmán queda nombrada Azafata con destino al Real Cuarto de la reina Isabel a partir del 22 de junio de 1859, hasta su fallecimiento el 24 de febrero de 1878.

\section{Guillermo Morphy, I Conde de Morphy. La educación del príncipe Alfonso}

Guillermo Morphy nació en Madrid el 29 de febrero de 1836, en la calle de la Ballesta $\mathrm{n}^{\mathrm{o}}$ 8, recibiendo las aguas bautismales en la Iglesia Parroquial de San Martín de Madrid. ${ }^{13}$ Su padre le dirigió hacia los estudios de jurisprudencia, aunque recibiría formación musical, atendiendo a una doble formación, la de abogado y la de músico. Tras finalizar en 1851 sus estudios de filosofía en el Colegio de don Vicente Santiago Masarnau, donde también recibe clases de música, continúa con los estudios de jurisprudencia en la facultad de Derecho de la Universidad Central de Madrid. ${ }^{14}$ A la 
muerte de su padre en 1858, se hace cargo de su prestigioso despacho, viéndose en la obligación de realizar constantes viajes, incluso al extranjero (Saldoni 57). A partir de 1863 se traslada a Bruselas donde continúa sus estudios de composición con F. J. Fétis y F. A. Gevaert, obteniendo grandes éxitos con algunas de sus composiciones para coro y orquesta. Es entonces, con motivo del sexto cumpleaños del príncipe Alfonso el 28 de noviembre de 1863, cuando la reina Isabel II honra a Guillermo Morphy con el cargo de Gentilhombre de Entrada, que pasa a ser de Interior el 24 de enero de 1864, recibiendo la remuneración de treinta mil reales anuales. ${ }^{15}$ De esta manera, Morphy se instala en el Palacio Real, escalera de damas, piso segundo, en una habitación contigua a la del príncipe. Según Ovilo y Otelo (338), en esta etapa de la vida del príncipe desde 1864 hasta 1868, Morphy inició un "saludable sistema de enseñanza", consagrándose a sus cuidados y sobre todo a su desarrollo moral y físico.

La Revolución de Octubre de 1868 provocó el exilio de la reina Isabel II a Francia. Pese a que el Gobierno Provisional suprimiría por decreto los cargos de Camarería Mayor de Palacio y de Gentilhombre de Cámara a Rosa Ferriz y su hijo Guillermo Morphy, ${ }^{16}$ ambos deciden seguir a la familia real en su destierro a París. Su lealtad a la Monarquía va a influir para que apenas dos años más tarde, en junio de 1870, Morphy sea elegido jefe de estudios y persona de confianza del príncipe durante sus estudios en el Colegio Teresiano de Viena. Según señala Julio Quesada Cañaveral y Piedrola, Conde de Benalúa, en sus Memorias, en esta decisión habría intervenido su tío, José Osorio y Silva, Marqués de Alcañices, más conocido como Duque de Sesto, quien ostentaba el cargo de Mayordomo Mayor de Palacio. Aunque lo más probable es que detrás del nombramiento estuviera también la decisión de la reina Isabel II, para quien Morphy reunía las condiciones idóneas como hombre de confianza por su probada lealtad a la monarquía, su catolicismo y su amplia ilustración. Además, ya era conocido en la corte y contaba con el afecto y cariño del joven príncipe de Asturias. Así lo relata el Conde de Benalua quien señala, entre otras cualidades, su espíritu constitucionalista:

Antes de salir de París, fue nombrado jefe de estudios del Príncipe, Don Guillermo Morphy, persona que eligió mi tío por sus antecedentes, fidelidad y gran ilustración. Era D. Guillermo Morphy y Guzmán, hijo, por su padre, de un noble irlandés (naturalizado español), y su madre Doña Rosa Guzmán, antigua azafata de la Reina Isabel, por lo que le unía estrecha amistad a mi tío Pepe. Era asimismo persona de vastísimos estudios, espíritu amplio, honradez y religiosidad acrisoladas y de una paciencia y constancia como he conocido a pocos en mi vida. Hombre absolutamente educado en los principios constitucionales, y aunque con el mayor respeto a sus Reyes, tenía la lealtad de manifestar siempre honradamente el respeto a la dignidad de los pueblos, sin la cual es difícil gobernar a la raza castellana. Morphy, después de la restauración, continuó siempre al lado del Rey, siendo su secretario particular. (55)

Otro testimonio que completa esta visión de su personalidad es el ofrecido por Pablo Casals. Este artista se sintió privilegiado al recibir educación por parte del Conde de Morphy, su protector, quien utilizaría los mismos libros de texto con los que había instruido a Alfonso XII. Casals ensalza la faceta de maestro que asumió Morphy en su vida y le califica como hombre del Renacimiento, por su versatilidad y amplia cultura, que englobaría en su persona diversos talentos, conocimientos y habilidades: estudioso e historiador, autor y músico, consejero de la corona y compositor, protector de las artes 
y poeta. En línea con ellos, señala que entre los intereses de Morphy se encontraban el arte y la literatura, la política y la filosofía, la ciencia y la sociedad y la música (Kahn $51)$.

El estudio de la correspondencia conservada en el Archivo de la Real Academia de Historia entre Guillermo Morphy y la Reina Isabel II $^{17}$ muestra que Morphy era consciente de la crucial misión de formar y preparar al príncipe como futuro rey de España, que sobrepasaba sus funciones anteriores como Gentilhombre. Se refiere a ello en estos términos:

$\mathrm{Al}$ aceptar el nombramiento con que V. M. se ha dignado honrarme, por más que el decreto solo hiciera mención de mi empleo de gentil-hombre, comprendí, Señora, toda su importancia y la gran responsabilidad que me imponía en el estado actual de la política española. Y precisamente acepté con vivísima esperanza de ser útil a V. M. y a mi país porque no teniendo yo ni personalidad ni importancia políticas, al desempeñar mi cargo podía dedicarme exclusivamente a vigilar la educación del Príncipe mi señor, bajo las inmediatas órdenes de V. M. y desentendiéndome por completo de toda exigencia o aspiración de partido. Ninguna misión puede haber más importante para un hombre honrado y caballero, sobre todo en el estado actual de nuestra desgraciada patria. ${ }^{18}$

La elección de Morphy hay que entenderla asimismo como respuesta a la necesidad de encontrar una persona de confianza que rompiera con el carácter político de los antiguos cortesanos, que habían llevado al fracaso el reinado de Isabel II. Los defensores de la Restauración borbónica en España deseaban acabar con la imagen de un espacio cortesano tan propio de tiempos anteriores de la Monarquía, caracterizada por la corrupción política y la práctica de la adulación e intriga. En la correspondencia a Isabel II, Morphy declara frecuentemente su carácter apolítico y su compromiso de no mencionar la política en sus conversaciones con el príncipe. Ejemplo de ello es la carta remitida el 29 de abril de 1874 a la reina en la que le recuerda: "también sabe V.M. que ni he sido, ni soy, ni quiero ser hombre político". ${ }^{19}$ También le menciona la lealtad de su familia hacia la corona: "como lo han hecho cumpliendo con su deber durante muchos siglos, todos los de mi familia en defensa de su religión y de sus reyes". Un factor que con toda probabilidad se habría tenido en cuenta para su nombramiento en el cargo de jefe de estudios. Más adelante, da a entender el verdadero alcance de su misión al incluir no solo la educación intelectual, sino también moral del príncipe:

Cualquiera que sea la suerte que la providencia destina a España en lo porvenir, es indudable que en ella han de tener la mayor influencia si es que no son causas decisivas el carácter y la inteligencia de Don Alfonso XII. El carácter, porque si a pesar de su clarísimo entendimiento no tiene S.A., la energía suficiente para considerar el trono como duro y espinosísimo deber y se deja deslumbrar por la adulación y por los placeres enemigos los más terribles de la Monarquía en todos los tiempos y países, no podrá llevar su misión ni restaurar su patria del triste estado a que la han conducido las discordias civiles. La inteligencia, porque si este augusto señor no la desarrolla convenientemente con el amor al estudio y al trabajo, no podrá tomar la iniciativa en la política, ni en los negocios y será forzosamente 
instrumento o tal vez víctima de las ambiciosas intrigas de tantos partidos políticos como allí se disputan el poder. ${ }^{20}$

Lo cierto es que estas palabras son una velada referencia a los errores del reinado de Isabel II, que Morphy consideraba víctima de las camarillas palaciegas y de las ambiciones políticas. Un suceso que no debería volver a producirse, para lo cual asumía que el propósito de la educación del príncipe sería "dar a España un rey capaz de hacer frente a las actuales circunstancias de una España visiblemente dividida, vigilando su educación intelectual y tratando de influir en su ánimo y de inculcarle las ideas de virtud, honor y de deber". ${ }^{21}$ Estos tres valores formaban parte de la imagen del caballero cristiano propia de la Edad Media, recuperada por el historicismo romántico de profundo calado en la España decimonónica. Así, la virtud del alma es entendida como amor a la patria, que exigiría, a cambio, una serie de deberes u obligaciones para con ella y que iría indefectiblemente acompañada del culto al honor, es decir, la defensa de la honra, por encima del provecho propio (García Morente 188-224).

Morphy atiende también a la educación del príncipe en religión, y señala su propósito ante Isabel II de "dirigir la educación de S. A y hacer de él un buen cristiano, un buen hijo y un príncipe ilustrado y digno de su patria". ${ }^{22}$ En la carta que el príncipe Alfonso escribe a Pio IX en junio de 1872 expresa sus fuertes convicciones religiosas e identifica el catolicismo y el modelo de caballería espiritual con la idea de nación española:

... quiera Dios y la Santísima Virgen concederme su amparo para que algún día pueda probar a V. S. cuan profundas raíces tiene en mi corazón la santa y gloriosa fe de mi Patria y de mis Padres y la inalterable firmeza con que como Príncipe católico y como caballero sostendré siempre nuestra Santa Religión, base de la nacionalidad española y blasón el más glorioso de su historia. $^{23}$

Hay que tener en cuenta, como subraya Espadas Burgos, que las contestaciones del príncipe en materias delicadas eran redactadas por Morphy y estas a su vez pasaban por la revisión de la propia reina (390).

Para cumplir con sus propósitos respecto al príncipe, Morphy elabora un programa de educación fruto de la reflexión y del conocimiento adquirido en diversas lecturas como el mismo confiesa a Isabel II: "desde la primera vez que se dignó nombrarme para el cuarto del Príncipe he pensado, leído, escrito y estudiado con el único objeto de acertar en este punto que es en mi concepto el más importante para la historia venidera de España". ${ }^{24}$ Concibe un sistema de enseñanza, en el que tiene en cuenta la importancia de "las primeras ideas", ya que a su entender estas "deciden del carácter para toda la vida"; por eso ve conveniente instruirle "con lecturas y conversaciones de un modo agradable", sensibilizándole sobre asuntos que más adelante deberá abordar, "de industria, o de economía política o de bellas artes con arreglo a su edad". ${ }^{25}$ De estas primeras clases que a diario Morphy impartía al príncipe durante su exilio en Francia, nos habla el conde de Benalúa, refiriéndose en particular a "la clase divertida" de historia contemporánea en la que Morphy se refería a las personas y acontecimientos "que enseñaban al Príncipe a ser Rey Constitucional y a imbuir en su espíritu la necesidad de regir a los pueblos modernos, y sobre todo, a España, ante todo, con las regalías de la Corona, con Constitución, garantía del pueblo y respetando el dogma sin supersticiones" (Conde de Benalúa 65). 
Ya en Austria la primera necesidad a la que se enfrentaba Morphy era la formación de una biblioteca con obras de historia y literatura de España, para lo que contaría con la ayuda y consejo del Marqués de Molíns, literato y político conservador, figura igualmente muy vinculada al príncipe. ${ }^{26}$ La correspondencia entre el príncipe Alfonso y el Marqués de Molíns en febrero de 1873, es de singular interés para el tema que nos ocupa. ${ }^{27}$ Así sabemos que el príncipe recibe obras de la Academia Española "encuadernadas con tanta delicadeza como buen gusto". ${ }^{28}$ Guiado por Morphy el príncipe se instruye en la historia de España y acomete la lectura del teatro español del Siglo de Oro y del romancero. En estas lecturas Morphy identifica nuestra nacionalidad y nuestro ser con los valores tradicionales de la fe, la patria o la familia en línea con las ideas del romanticismo historicista alemán de Herder y los hermanos Schlegel, importado por Böhl de Faber (García Álvarez de la Villa, "Regeneracionismo" 459). Este había traído a España el interés por la recuperación de la Edad Media cristiana, el estilo gótico como su arte genuino, el drama del Siglo de Oro y el romancero (Flitter). También las obras literarias y los escritos académicos del Marqués de Molíns o las recién publicadas Cantigas de Alfonso el Sabio servían para estos propósitos. Además el príncipe adquiriría la edición de las obras completas en 12 tomos de Schiller (1838) de las que apreciaría sobre todo sus dramas de juventud como Die Rüber o Kabale und Liebe. Este autor exponente del idealismo alemán ejercía una influencia aún mayor que la de Goethe entre la juventud de Viena, según señalaba el príncipe en su correspondencia con Molíns. ${ }^{29}$

Por su parte, el significado de estas lecturas no se le escapa al Marqués de Molíns, quien muestra su satisfacción ante las mismas y señala su relevancia en quien ha "de ejercer en España el Poder más fuerte y más salvador de la Historia", ya que arguye Molíns, si bien "el positivismo, la realidad, la prosa, han de formar necesariamente parte muy principal de la gobernación de los Estados", esta no cumple finalmente su papel cuando está ausente en los gobernantes "el elemento poético en las ideas y en las acciones". "Molíns expresa en el contexto de la República española, una crítica a las tendencias realistas y materialistas de la época, que entraban en colisión con el espiritualismo. ${ }^{31}$ Considera que "la reacción prosaica y positiva va demasiado lejos, y que la ruina de España y de las razas latinas se consumará irremediablemente, si los Príncipes creen justo todo lo útil y útil todo lo posible". ${ }^{32}$ Con ello manifiesta su rechazo hacia las doctrinas utilitaristas de la Ilustración, cuyos excesos eran denunciados también por otros intelectuales de la época y por el propio Conde de Morphy ante la pérdida de los valores tradicionales, motivada por el escepticismo, el racionalismo, el abandono de la fe y el materialismo. De manera similar a Molíns, Morphy tras vivir los sucesos revolucionarios de la Commune en Paris en 1871 había manifestado que la "anarquía moral e intelectual" era resultado de los excesos de las ideas de la Ilustración, surgidas de la revolución del 93 en Francia, que habían traído el ateísmo, desorganizando la sociedad y la familia, por lo que instaba a que "cada pueblo debe guardar y guardará su religión, su filosofía, y su forma de gobierno".33

Si las lecturas constituían una buena forma de adoctrinar al príncipe, también contribuía a ello la asistencia al teatro, donde el príncipe disfrutaba al ver representadas las obras de Shakespeare, como Otello consideradas por él mismo en su carta a Molíns, una "escuela de la vida". Asimismo mostraba su deseo de ver representadas otras piezas teatrales de Schiller y Goethe. Otra obra que entusiasmaría al príncipe sería La vida es sueño de Calderón, ${ }^{34}$ interpretada por los actores del Teatro del Emperador, con motivo de su cumpleaños. La prensa austriaca encuentra en la asistencia del príncipe a la representación "un rasgo de amor a las glorias de su país", por lo que Morphy aconseja divulgar la noticia en los periódicos españoles, contribuyendo a proyectar una imagen 
cercana del futuro rey. ${ }^{35}$ Lo cierto es que el drama de Calderón se consideraba un símbolo de unión espiritual entre países de tradición cristiana, además de una muestra del genio español. ${ }^{36}$

En la formación integral del príncipe entraban tanto las visitas a museos, monumentos y ciudades históricas como la asistencia a conciertos o al teatro. En línea con las tendencias pedagógicas modernas en Europa, Morphy atendía no sólo a la educación de la inteligencia, sino también del sentimiento, de la emoción y de la estética. Tampoco olvidaba Morphy el desarrollo físico del príncipe, en base a una vida metódica que le pusiera en contacto con la naturaleza y con la práctica de ejercicios corporales. ${ }^{37}$ En palabras de Ovilo y Otelo:

Acompañóle en excursiones y viajes; le acostumbró a todo género de vida y a todo linaje de costumbres; visitó con él fábricas, museos y establecimientos varios; le llevó a Venecia, Padua, Verona y al Tirol después; le inspiró amor a las artes; examinó con él la gran Exposición Internacional, donde conoció Morphy a Soberanos y a celebridades; logró que se hiciera querido y popular en Viena, y consiguió, en fin, que las altas prendas, las relevantes dotes innatas en D. Alfonso de Borbón creciesen y se desarrollasen lozanas y robustas como las flores en los huertos y los robles en las montañas. (341)

En abril de 1874 Morphy escribe a la reina mostrándole su parecer en contra de la opinión de Cánovas de interrumpir los estudios del príncipe en Viena para iniciar sus estudios militares. Si bien reconoce la importancia de la formación militar en los príncipes europeos, considera esta como un complemento a su plan de enseñanza, ya que a su entender el porvenir del príncipe en España “depende más de su carácter, de su inteligencia, de su tacto para manejar a los hombres que no de sus conocimientos puramente científicos en la ciencia militar". ${ }^{38}$ Insiste en la necesidad de que el príncipe pueda continuar aún la formación de su temperamento y profundizar en estudios como "la historia de España, la historia general y las nociones de derecho político, de derecho internacional y de economía política”. Estas materias en las que el mismo Morphy estaba formado en base a sus estudios de jurisprudencia completarían la formación del príncipe y le ayudarían a comprender sus funciones dentro de la monarquía constitucional. El mismo príncipe era consciente de la necesidad de una formación constitucional, y en línea con los propósitos de su maestro llega incluso a sugerir a su madre, Isabel II, la conveniencia de acometer los estudios universitarios tras finalizar sus estudios en el Colegio Teresiano (Larios 2003: 26).

Finalmente, de acuerdo a las recomendaciones realizadas por Morphy, el príncipe culmina sus exámenes en julio de 1874, iniciando en el mes de septiembre su formación militar en la prestigiosa academia militar de Sandhurst, tal como deseaba Cánovas. Apenas tres meses más tarde se produce el pronunciamiento del general Martínez Campos en Sagunto, y a continuación es proclamado Alfonso XII rey de España. Al frente de la monarquía llega un joven monarca en contacto con la Europa moderna, dispuesto a aunar todos los esfuerzos para la modernización de España, cumpliendo las máximas del manifiesto de Sandhurst, en donde "pagaba tributo a la tradición en las fundamentales a la religión y de la monarquía representativa" y recordaba la antigua máxima, "progresar conservando", lo que no impediría seguir "con seguros pasos, la marcha progresiva de la civilización". 39 
Los propósitos regeneradores de Alfonso XII eran explicados por el propio Morphy a Julio Nombela en una "larga y sustanciosa conferencia", poco antes del pronunciamiento de Sagunto:

Después de tributar entusiastas elogios a las en su concepto excepcionales cualidades de D. Alfonso, me aseguró que el principal propósito del joven monarca era cambiar completa y radicalmente el espíritu del país. Iría poco a poco quitando importancia a lo que hasta entonces se había calificado de política, dándoselas a la educación e instrucción de todas las clases sociales, a la cultura, a la industria, al comercio, a las ciencias, las letras y las artes.El bello ideal del monarca era transformar España, hacer que entrase de lleno en el concierto europeo, asemejarse más a Carlos III que a los demás reyes de la dinastía que representaba, y lograr de este modo que el progreso intelectual y moral reemplazase a las intrigas políticas y financieras, a las discordias civiles; en una palabra, al lamentable atraso en que después de la gloriosa guerra de la Independencia había vivido España. (Nombela 288)

Podemos deducir casi con toda seguridad, que detrás del ideal de Alfonso XII, estaría la influencia de Guillermo Morphy, para quien la Monarquía constitucional partiría de la tradición al tomar como ejemplo el reinado de Carlos III, con un monarca preparado para hacer frente a los nuevos desafíos de regeneración. Morphy confiaba en que España, sustentada en los pilares de la monarquía y el catolicismo, alcanzaría un periodo de estabilidad y paz social, haciendo posible que con la fuerza de los partidos constitucionalistas se situara en la Europa moderna. Para ello sería necesario que los españoles superasen sus pasiones políticas y unidos por un mismo sentimiento patriótico trabajaran juntos por la regeneración y modernización del país (García Álvarez de la Villa, "Regeneracionismo" 456). Estas ideas quedan reflejadas en su discurso de apertura en la Sección de Bellas Artes del Ateneo de Madrid $^{40}$ donde considera necesario la "regeneración artístico-industrial" de España siguiendo el ejemplo de otros países europeos (458).

Tabla 1. Distinciones

\begin{tabular}{|l|l|}
\hline Nombre y apellidos & \multicolumn{1}{|c|}{ Títulos y distinciones } \\
\hline Juan Morphy y Porro & Orden de Alcántara \\
\hline $\begin{array}{l}\text { Guillermo Morphy y y } \\
\text { Ferriz de Gúzman }\end{array}$ & $\begin{array}{l}\text { Gran Cruz de la Orden Pontificia de San Gregorio Magno Gran Cruz } \\
\text { de la Imperial de Francisco José de Austria Gran Cruz de la Orden } \\
\text { de Cristo de Portugal } \\
\text { Sran Oficial de la de Leopoldo de Bélgica Maestranza de Sevilla } \\
\text { Conde de Morphy }\end{array}$ \\
\hline
\end{tabular}

Establecida la Restauración Borbónica en noviembre de 1875, Morphy fue nombrado secretario particular de Alfonso XII, quien además en recompensa a sus servicios le concedería la Cruz Grande de San Gregorio el Magno en $1875^{41}$ y el título de Conde de Morphy en 1882. Este mismo año, se une en matrimonio con la Baronesa Cristina Hagyi de Scysinger (1852-1928), ${ }^{42}$ natural de Budapest, una mujer de vasta cultura, antigua alumna de música de F. Liszt. Su única hija, Cristina Morphy, también se 
dedicaría al mundo de la música. Tras el fallecimiento del monarca el 26 de noviembre de 1885, la Reina Regente le renueva su confianza, manteniéndole en el puesto con el sueldo anual de quince mil pesetas. ${ }^{43}$

Durante la Restauración borbónica el Conde de Morphy mostró su preocupación por la situación de la música española, luchando por la defensa del arte nacional y la ópera española, además de llevar a cabo una intensa actividad como mediador cultural. Morphy ofreció apoyo y protección a muchos jóvenes artistas, entre ellos a Tomás Bretón, Isaac Albéniz y Pablo Casals, sirviendo de intermediario con la Corona, que les propició pensiones para su formación en el extranjero. Como compositor estrenó obras en Dresde, Bruselas, París, Viena y Madrid. También destacó como crítico musical, a través de la colaboración con importantes periódicos de la época como La Ilustración Española y Americana, El Imparcial, La Correspondencia Musical o La España Moderna. Fue presidente de la Sociedad de Conciertos (1884), académico de número de la Sección de Música en la Academia de Bellas Artes de San Fernando (1887), presidente de la Sección de Bellas Artes en el Ateneo de Madrid (1886). En esta última institución fueron numerosas sus conferencias y la programación de conciertos, en línea con su pensamiento regeneracionista (García Álvarez de la Villa, "Regeneracionismo"). También estuvo presente en otros proyectos reformadores: la fundación del Instituto Filarmónico, como alternativa al Conservatorio de Madrid, que en línea con otros establecimientos europeos ofrecía enseñanzas a todas las clases sociales (García Álvarez de la Villa, "El instituto"); la rehabilitación de la fábrica de la Moncloa, que tanto renombre había adquirido en el reinado de Carlos III, a través de la formación de una sociedad anónima que contaba con la presencia de Alfonso XII; el proyecto de reforma penitenciaria con la creación de un correccional moderno para jóvenes, siguiendo el ejemplo de otras naciones europeas y americanas, al cual el Rey y la Princesa de Asturias contribuyeron con importantes donativos $;^{44}$ por último, la constitución de la Sociedad Geográfica para la civilización de África, donde Alfonso XII aparece como presidente de la junta directiva.

Tabla 2. Cargos de la familia Murphy en España, siglos XVIII y XIX

\begin{tabular}{|l|l|}
\hline Nombre y apellidos & \multicolumn{1}{|c|}{ Cargos y distinciones } \\
\hline Juan Murphy Elliot & $\begin{array}{l}\text { Fundador de compañía Juan Murphy y Cía. Propietario de dos } \\
\text { buques mercantes "La esperanza" y "El ligero" } \\
\text { Director de la Compañía de Navieros de Málaga } \\
\text { Director de La Marítima } \\
\text { Casa Morphy y Porro } \\
\text { Fabrica de aguardientes en Casabermeja }\end{array}$ \\
\hline Mateo Morphy y Porro & Casa Gordon \& Murphy Compañía Marítima de Málaga \\
\hline Juan Morphy y Porro & $\begin{array}{l}\text { Agente de la Casa Gordon \& Murphy Coronel de Infantería } \\
\text { Hábito de la Orden de Alcántara }\end{array}$ \\
\hline
\end{tabular}




\begin{tabular}{|l|l|}
\hline José Morphy y Martí & $\begin{array}{l}\text { Alcalde de Navalcarnero } \\
\text { Juez de primera instancia en Almería Fiscal de la Audiencia de } \\
\text { Sevilla, Juez de la Corte de Madrid } \\
\text { Magistrado honorario de la Audiencia de Albacete Fiscal de la Real } \\
\text { audiencia Territorial de Sevilla Gentilhombre de Cámara } \\
\text { Jurisperito (asuntos diplomáticos) }\end{array}$ \\
\hline $\begin{array}{l}\text { Guillermo Morphy y } \\
\text { Ferriz de Gúzman }\end{array}$ & $\begin{array}{l}\text { Gentilhombre de Entrada Gentilhombre del Interior Tutor del } \\
\text { príncipe Alfonso Título de Conde de Morphy Secretario de Alfonso } \\
\text { XII } \\
\text { Secretario de la Reina Regente María Cristina Presidente de la } \\
\text { Sociedad de Conciertos } \\
\text { Presidente de la Sección de Bellas Artes del Ateneo }\end{array}$ \\
\hline
\end{tabular}

\section{Conclusiones}

Este trabajo confirma el éxito de la integración social de la familia Murphy en España gracias al reconocimiento de sus pruebas de nobleza por la Corona española y a estrategias matrimoniales que supusieron su rápida ascensión dentro de la Monarquía española a lo largo de los siglos XVIII y XIX. Se constatan fuertes vínculos familiares entre sus miembros que facilitan la pervivencia de sus negocios y su primacía en el comercio internacional durante varias generaciones. La red familiar Murphy está presente no sólo en el comercio, sino también en el ejército y en la administración. Sus vínculos de fidelidad a la Monarquía borbónica son valores que se transmiten de unas generaciones a otras y que explican el ascenso a posiciones de confianza dentro de la Corte de los Borbones, que les recompensó otorgándoles distinciones y títulos nobiliarios.

Por otra parte, debe de reconocerse el crucial papel desempeñado por Guillermo Morphy en la formación del carácter e inteligencia del príncipe Alfonso, tomando como referencia el modelo de caballero según la moral cristiana y la tradición escolástica, que en el siglo XIX se renueva bajo la influencia del romanticismo historicista y de las tendencias espiritualistas de la época. Es indudable que Morphy ideó un programa de enseñanza en el que enfatiza la formación humanística, con el conocimiento de la historia de España, de sus tradiciones, de su ser como nación, que combina asimismo con una formación integral del príncipe, atendiendo a los ejercicios corporales y las visitas a museos, fábricas y otros establecimientos y lugares de interés, además de instruirle en el derecho constitucional. Todo ello cumple el propósito de formar un rey constitucional capaz de liderar la regeneración de la nación, situando a España en la Europa moderna, cumpliendo con los principios ideológicos anunciados en el manifiesto de Sandhust. Un monarca cuya imagen se identificara más que con sus inmediatos antecesores, con el reformista Carlos III. Consideramos, en suma, que Morphy contribuyó de manera notoria a hacer posible la causa de la Restauración borbónica, gozando de la máxima confianza del rey, quien le otorgó el título de Conde de Morphy en reconocimiento de sus servicios a la Corona y le nombró su secretario particular. Desde esta posición continuó como consejero del monarca, siendo reconocido sobre todo por su relevante papel en el mundo de la cultura y en la protección de los músicos 


\section{Notas}

${ }^{1}$ Esta investigación forma parte de mi Tesis Doctoral sobre el Conde de Morphy, dirigida por Ramón Sobrino Sánchez en la Universidad de Oviedo.

${ }^{2}$ El auge de los estudios sobre la corte española en la España Contemporánea es motivo actual de interés. Ejemplo de ello lo tenemos en el proyecto de investigación "Corte, Monarquía y Nación liberal (18331885). En torno al Rey y la modernización política de España en el siglo XIX (HAR2015-66532-P) financiado por el MINECO/FEDER. Su publicación más reciente Raquel Sánchez y David San Narciso (coords.). La cuestión de Palacio. Corte y cortesanos en la España contemporánea. Granada, Comares, 2018.

${ }^{3}$ El apellido irlandés sufrió la adaptación a la fonética española, encontrándose tanto la forma Murphy como Morphy entre individuos de una misma rama genealógica.

${ }^{4}$ Otras formas anglicadas son Murchoe, Murrough o Murphie.

${ }^{5}$ Originariamente establecida en el Castle Ellis, en la Baronia de Ballghkeen (condado de Wexford).

${ }^{6}$ Juan Murphy. Chancilleria de Granada. Exp. 13219.

7 Datos tomados de la Genealogía perteneciente al archivo privado del VI Conde de Morphy. Agradecemos a Don Jaime Caruana su comunicación.

${ }^{8}$ Tomás Murphy. AGI: INDIFERENTE, 2113, N. 34.

${ }^{9}$ Datos tomados de los archivos privados del VI Conde de Morphy y de la autora.

${ }^{10}$ Juan Morphy y Hermet . Archivo Histórico de Protocolos. Protocolo consular 1894-1905. Consulado de España en Suiza. (1897).

${ }^{11}$ Guillermo Morphy . AGP Sección personal, caja 719, exp. no 11.

12 José Morphy. Certificado defunción. 0041.

13 Archivo Histórico Diocesano de Madrid: Partida de bautismo de Guillermo Morphy. Libro $68^{\circ}$ de bautismos de la parroquia de San Martin de Madrid (fol. 282; imagen 570).

${ }^{14}$ Guillermo Morphy. Archivo Histórico Nacional, Sig. UNIVERSIDADES, Leg. 4485, Exp.15. 063.

${ }^{15}$ Guillermo Morphy. Expediente personal. Palacio Real. Caja 719-10.

${ }^{16}$ Rosa Ferriz de Morphy. Expediente personal. Caja 16015-31

17 Archivo de la Real Academia de la Historia (ARAH). Cartas y documentos cruzados entre la Reina Isabel II y Guillermo Morphy que abarcan desde el 17 de febrero de 1872 al 16 de julio de 1874 .

${ }^{18}$ Carta entre Guillermo Morphy a Isabel II. 10 de diciembre de 1872. ARAH: 9/6960, legajo XXI, ${ }^{\circ}$ 245-246.

${ }^{19}$ Carta de Guillermo Morphy a Isabel II. 28 de abril de 1874. ARAH: 9/6960, legajo XXI, nº 322.

${ }^{20}$ Ibidem.

${ }^{21}$ Ibid.

${ }^{22}$ Carta de Guillermo Morphy a Isabel II. 20 de enero de 1873. En ARAH: 9/6960, legajo XXI, no 254.

${ }^{23}$ Carta de D. Alfonso a S. S. Pío IX. 14 de junio de 1872. ARAH: 9/6952, legajo XIII, no 227.

${ }^{24}$ Carta de Guillermo Morphy a Isabel II. 13 de abril de 1874. ARAH: 9/6960, legajo XXI, no 320.

${ }^{25}$ Carta de Guillermo Morphy a Isabel II, 20 de marzo de 1872. ARAH: 9/6960, legajo XXI, no 207.

26 Mariano Roca de Togores y Carrasco (1812-1889), Marqués de Molíns. Fundador de diversas instituciones académicas como el Liceo Artístico y Literario, detentó el cargo de ministro de Comercio, Instrucción y Obras públicas (1847) y fue gentilhombre de cámara (1848). Isabel II le nombró jefe del partido conservador durante su estancia en París, cargo del que renunció en favor de Cánovas del Castillo.

${ }^{27}$ Publicada en "Don Alfonso XII y el Marqués de Molíns". La basílica teresiana, año VII, n 80,15 de agosto de 1912, pp. 247-252.

${ }^{28}$ Ibidem, p. 249.

${ }^{29}$ Ibid., p. 250.

${ }^{30}$ Ibid., pp. 250-251

${ }^{31}$ Sobre el asunto puede consultarse Lissorgues, Yvan y Sobejano, Gonzalo (coords.), Pensamiento y literatura en España en el siglo XIX, Idealismo, positivismo, espiritualismo, Toulouse, Presses Universitaires du Mirail, 1998. 
32 “Don Alfonso XII y el Marqués de Molíns"..., op. cit, 251.

${ }^{33}$ Morphy, G. «De la ópera española». La Ilustración española y Americana, año XV, nº XV, 25 de mayo de 1871 , p. 250.

${ }^{34}$ Carta de Guillermo Morphy a Isabel II. 24 de enero de 1873. ARAH: 9/6960, Legajo XXI, $n^{\circ} 256$.

${ }^{35}$ Carta de Guillermo Morphy a Isabel II. 26 de febrero de 1873. ARAH: 9/6960, Legajo XXI, no 263.

${ }^{36}$ Sobre el particular puede leerse, Julius Wilhelm: "La critica calderoniana, en los siglos XIX y XX, en Alemania". Cuadernos Hispanoamericanos, n. 73, enero 1956, pp. 47-56.

${ }^{37}$ Carta de Guillermo Morphy a Isabel II. 24 de abril de 1874. ARAH: 9/6960. Leg XXI, nº 321

${ }^{38}$ Carta de Guillermo Morphy a Isabel II. 24 de abril de 1874. ARAH: 9/6960, legajo XXI, no 321.

${ }^{39}$ El manuscrito del manifiesto de Sandhurst se conserva en la Real Academia de Historia: Archivo de Isabel II, Signatura: 9/6952, Legajo XIII, No 247. (1 de diciembre de 1874). Puede consultarse en línea en http://bibliotecadigital.rah.es/dgbrah/es/consulta/registro.cmd?id=13633

${ }^{40}$ Morphy, G. «El arte español en general y particularmente nuestras artes suntuarias». Discurso leído en la apertura de la Sección de Bellas Artes del Ateneo Científico y Literario de Madrid por el Sr. conde de Morphy. Madrid, Imprenta y Fundición de Manuel Tello, 1886, p. 6 .

${ }^{41}$ El comercio. Año XXXIII, no 11633,5 de noviembre de 1875, p. 2.

${ }^{42}$ Cristina Hagyi. Archivo Histórico Nacional. CONSEJOS, 8971, A.1882, Exp.2 6.

${ }^{43}$ Guillermo Morphy. Archivo General de Palacio. Exp. Personal. Sig. 719-10.

44 “Reforma penitenciaria”. Boletín de la revista general de legislación y jurisprudencia, vol. 49, Madrid, imprenta de la revista de Legislación, 1876. 352. Más adelante se convertiría en la escuela de reforma para jóvenes Santa Rita, impulsada por el jurista y político conservador Francisco Lastres.

\section{Obras citadas}

Benalúa, Conde de. Memorias del Conde de Benalúa, Duque de San Pedro de Galatino. Vol. 1. Madrid: Blass, 1924.

Bernal Rodríguez, Antonio Miguel, coord. El comercio libre entre España y América latina, (1765-1824). Madrid: Fundación Banco Exterior, 1987.

Blanco White, José María. Autobiografía de Blanco White. Sevilla: Edición de Antonio Garnica, 1988. . Cartas de España. Madrid (1807). T. 3. Biblioteca El Sol, 1991.

Bustos Rodríguez, Manuel. Cádiz en el sistema atlántico. La ciudad, sus comerciantes y la actividad mercantil (1650-1830). Universidad de Cádiz: Sílex ediciones, 2005.

Cadenas y Vicent, Vicente de. Caballeros de la Orden Alcántara siglo XIX. Madrid: Editorial Hidalguía, 1991.

Chauca García, Jorge. 2003. "Irlandeses en el comercio gaditano americano del setecientos". I Coloquio Internacional Los Extranjeros en la España Moderna. Málaga. V. I. Editores: Ministerio de Ciencia e Innovación, 2003. 267-77.

Espadas Burgos, Manuel. Alfonso XII y los orígenes de la Restauración. Madrid Editorial CSIC, 1990.

Fernández Moya, Rafael. 2007. "The Irish Presence in the History and Place Names of Cuba". Irish Migration Studies in Latin America 5.3 (2007): 189-98.

Fannin, Samuel. "The Irish Community in Eighteenth-Century Cadiz". Irish Migrants in Europe after Kinsale, 1602-1820. Eds. Thomas O'Connor and Mary Ann Lyons. Dublín: Four Courts Press, 2003. 135-48.

."Spanish Archives of primary Source Material". 2013. 12 October 2018. https://www.irishancestors.ie/wp-content/uploads/2013/02/Fannin-SpanishArchives-of Primary-Source-Material.pdf. 
Flitter, Derek. 2015. Teoría y crítica del romanticismo español. Madrid: Ediciones Akal, 2015.

García-Álvarez de la Villa, Beatriz and Kevin Kevin. "Terrys in Spain and LatinAmerica: Exile and Rise of an Irish Merchant Family". Estudios Irlandeses 11 (2016): 69-81.

García Álvarez de la Villa, Beatriz. "El Instituto Filarmónico del Conde de Morphy y su escuela de canto en el establecimiento del drama lírico nacional". Cuadernos de Música Iberoamericana 29 (2016): 81-109.

. "Regeneracionismo musical en el Ateneo de Madrid bajo la presidencia del Conde de Morphy". Revista de Musicología XL, 2 (2017): 449-87.

Gámez Amián, Aurora. Málaga y el comercio colonial con América (1765-1820). Málaga: Editoral Miramar, 1994.

García Morente, Manuel. Obras completas. V. II. Edición de Juan Miguel Palacios y Rogelio Rovira. Madrid: Fundación Caja de Madrid, 1996.

González Mireles, Gabriela Sofía. Retrato de un mercader: Thomas Murphy Porro. Tesis Doctoral: Universidad Nacional Autónoma de Mexico, 2009.

2010. "Retrato de un comerciante malagueño en Veracruz: Tomás Murphy Porro". Ulúa 15 (enero-junio 2010): 9-28.

. "La cuestión del comercio novohispano llevado a las Cortes por la última legislatura novohispana en las exposiciones del diputado Tomás Morphy (18211822)". La Constitución de Cádiz de 1812 y su impacto en el Occidente Novohispano. Coords. José Luis Soberanes Fernández y Eduardo Alejandro López Sánchez. México: Universidad Nacional Autonómica de México, 2015. 233-247.

Higueras Castañeda, Eduardo. Manuel Ruiz Zorrilla (1833-1895). Tesis Doctoral: Universidad de Castilla La Mancha, 2014.

Jiménez Codinach, Guadalupe. La Gran Bretaña y la Independencia de México 18081821. México: FCE, 1991.

Kahn, Albert Eugene. 1970. Reflexions de Pau Casals. Barcelona: Antoni Bosch, 1970.

Lario, Ángeles. “Alfonso XII. El rey que quiso ser constitucional”. Ayer 52 (2003): 1538.

Lario, María del Carmen. "The Irish Traders of Eighteen Century in Cadiz". Irish and Scottish Mercantile Networks in Europe and Overseas in the Seventeenth and Eighteenth Centuries. Eds. David Dickson, Jan Parmentier and Jane H. Ohlmeyer. Gent: Academia Press, 2007. 211-30.

Morphy, Guillermo. "El arte español en general y particularmente nuestras artes suntuarias". Discurso leído en la apertura de la Sección de Bellas Artes del Ateneo Científico y Literario de Madrid por el Sr. Conde de Morphy. Madrid: Imprenta y Fundición de Manuel Tello, 1886. 1-58.

Muñoz González, Ignacio A. Arqueología y política en españa en la segunda mitad del siglo XIX: Juan Facundo Riaño y Montero. Tesis Doctoral: Universidad Autónoma de Madrid, 2016.

Nombela, Julio. Impresiones y recuerdos. Tomo IV. Madrid: Ed. La última moda, 1911.

O'Hart, John. Irish Pedigrees, vol. I. Dublin: James Duffy and Co, 1892 (forth edition). 553-57.

Ovilo y Otero, Manuel. "El caballero Morphy". Escenas contemporáneas, Tomo II. Madrid: Tip. de Manuel G. Hernandez, 1883. 336-42.

Recio Morales, Óscar. "Una nación inclinada al ruido de las armas. La presencia irlandesa en los ejércitos españoles, 1580-1818: ¿la historia de un éxito?”. Tiempos modernos 4, 10 (2004): 1-15. 
- "Un estado de la cuestión". Redes de nación y espacios de poder: la comunidad irlandesa en España y la América española 1600-1825. Valencia: Albatros Ediciones, 2012. 37-52.

Saldoni, Baltasar. Diccionario Biográfico-Bibliográfico de Efemérides de Músicos Españoles. Tomo II. Madrid: Imp. de D. Antonio Perez Dubrull, 1880.

Sánchez, Raquel. "Los gentilhombres de palacio y la política informal en torno al monarca en España (1833-1885)". Aportes 96 (2018): 33-64.

Wilhelm, Julius. "La critica calderoniana, en los siglos XIX y XX, en Alemania". Cuadernos Hispanoamericanos 73 (enero 1956): 47-56.

\section{Periódicos}

"Reforma penitenciaria". Boletin de la revista general de legislación y jurisprudencia, vol. 49, Madrid, imprenta de la revista de Legislación, 1876. 352.

El comercio. Año XXXIII, n ${ }^{\circ} 11633,5$ de noviembre de 1875. 2.

Morphy, G. "De la ópera española". La Ilustración española y Americana, año XV, no XV, 25 de mayo de 1871. 250.

“Don Alfonso XII y el Marqués de Molíns". La basílica teresiana, año VII, nº 80, 15 de agosto de 1912. 247-52.

\section{Archivos}

Archivo familiar Galbis y Dolz del Espejo. VI Conde de Morphy.

Archivo familiar de la autora.

Chancillería de Granada.

Archivo General de Indias.

Archivo General de Palacio.

Archivo Histórico de Protocolos.

Archivo Histórico Diocesano de Madrid.

Archivo Histórico Nacional.

Archivo de la Real Academia de la Historia.

Received: 21 October 2018 Revised version accepted: 21 January 2019

Beatriz García-Álvarez de la Villa es profesora del Real Conservatorio Superior de Música de Granada. Licenciada en Geografía e Historia por la Universidad de Oviedo, donde se especializó en Musicología. Actualmente está realizando una Tesis doctoral en la Universidad de Oviedo sobre Guillermo Morphy, el Conde de Morphy. Ha publicado otros artículos en revistas como Revista de Historia naval, Revista de Musicología, Cuadernos de Música Iberoamericana y La Gaceta de la RSME.

beatrizalvarezdelavilla@gmail.com 